\title{
EDUCAÇÃO PROFISSIONAL NA ORDEM DO CAPITAL EM PARNAÍBA/PI: APRENDENDO A SER TRABALHADOR NA SOCIEDADE DO (DES) EMPREGO
}

\section{PROFESSIONAL EDUCATION IN ORDER OF CAPITAL IN PARNAÍBA / PI: LEARNING TO BE WORKER IN SOCIETY (UN) EMPLOYMENT}

\author{
Tânia Serra Azul Machado Bezerra ${ }^{i}$ \\ Cloris Violeta Alves Lopes ${ }^{\text {ii }}$ \\ Maria Luzirene Oliveira do Nascimento ${ }^{i i i}$
}

RESUMO:

Este estudo é resultado de pesquisa realizada no Grupo de Estudos Marxistas Piauiense, tem como lócus a formação da juventude direcionada à Educação Profissional e a relação desta última com a inserção no mercado de trabalho em Parnaíba-Pl. Durante a investigação, propomos uma análise sobre a formação destinada aos jovens da classe trabalhadora e a sua inserção no mundo do trabalho. Nesta perspectiva, compreendemos a juventude enquanto segmento social e histórico ao tempo que indagamos sobre a influência social/econômica/política e ideológica das relações capitalistas na formação desta instância. Nossas reflexões nutriram-se de observações, entrevistas/questionários e leituras de fontes primárias coletadas no Centro de Educação Profissionalizante - CEEP, em Parnaíba/PI. Ressaltamos a importância do debate sobre as metamorfoses no mundo do trabalho contemporâneo e a problemática da empregabilidade para a compreensão da relação entre mercado de trabalho e educação no CEEP. Refletimos ainda sobre a dualidade existente entre ensino técnico e educação integral, como causa da divisão entre trabalho manual e trabalho intelectual.

Palavras-chave: Educação Profissional - Empregabilidade - Juventude Trabalho

\begin{abstract}
ABSTRAT
This study is the result of research conducted in Piauiense Marxist Study Group, is the locus of youth training directed at Professional Education and the relationship of the latter with the insertion in the labor market in Parnaíba-PI. During the investigation, we propose an analysis of the training to young working class and its inclusion in the workplace. In this perspective we understand the youth segment as social and historical time to inquire about the influence that social / economic / political and ideological formation of capitalist relations in this instance. Our reflections nourished up observations, interviews / questionnaires and readings of primary sources collected at the Center for Professional Education - CEEP on Parnaíba / IP. We emphasize the importance of the debate on the metamorphoses in the world of contemporary work and the issue of employability for understanding the relationship between labor market and education at CEEP. Still reflect on the duality between technical education
\end{abstract}


and comprehensive education as a cause of division between manual and intellectual labor.

Keywords: Professional Education - Employment - Youth - Labor

\section{INTRODUÇÃO}

Nossa investigação surge da necessidade de analisar/refletir acerca da relação entre Educação Profissional, mundo do trabalho e juventude da classe trabalhadora na cidade de Parnaíba/Piauí. Nesse sentido, propomos debate em torno do cenário socioeconômico parnaibano e a influência deste nos processos formativos em âmbito escolar. O objetivo é compreender a intrínseca relação entre escola e modelo de produção instaurado pela sociabilidade do capital contemporâneo.

Frente tal pressuposto, a Educação Profissional no Brasil Piauí/Parnaíba tem se constituído como uma modalidade de ensino bastante favorável ao contexto das propostas de desenvolvimento social capitalista, visando suprir tanto a demanda de mão de obra técnica e especializada, como oferecer aos jovens maiores oportunidades de acesso ao mercado de trabalho. Essa perspectiva tem gerado diversos debates a nível nacional/mundial no que se refere às políticas públicas para a consolidação dessa modalidade de ensino. Tais políticas, voltadas para a formação técnica e profissional, correspondem ao sistema produtor de mercadorias e a estrutura social em que vivemos, na qual encontramos evidenciado o valor da educação com caráter mercadológico.

Diante das dificuldades de emprego encontradas no cenário econômico mundial/brasileiro/parnaibano e as sucessivas crises do capitalismo do tempo presente, nos preocupamos neste estudo, em analisar a juventude enquanto segmento social atingido por esse fenômeno, considerando o impacto da educação para o trabalho, uma possível conquista do emprego e construção dos meios de sociabilidade desse jovem. Neste âmbito buscamos ainda compreender as contradições que emergem de tal proposta formativa vez que neste caso a educação é restringida a um apêndice econômico, negligenciando, por exemplo, uma formação humana integral (GRAMSCI, 
2004). Faz-se necessário um atento olhar ao discurso oficial que vincula educação e empregabilidade - o âmbito educativo isoladamente não dá conta de gerar emprego e renda. Desta feita mudanças estruturais no âmbito produtivo na perspectiva da redistribuição de riquezas precisariam acontecer.

Nesta lógica, procuramos compreender as práticas de Educação Profissional experienciadas em nosso país/estado/cidade e suas relações com a manutenção da estrutura socioeconômica vigente. Em análise à categoria dualismo existente no processo de formação profissional, indagamos a respeito de como estas práticas têm sido vivenciadas na formação do jovem trabalhador parnaibano e de que forma ações pedagógicas dialogam com o modelo de desenvolvimento social vigente e suas reais intenções. Ressaltamos ainda, como a Educação Profissional e Tecnológica tem sido percebida enquanto espaço de mobilidade social para a juventude.

Nossa pesquisa, em andamento, está sendo vivenciada em uma instituição de Educação Técnica e Profissional, o Centro Estadual de Estudos Profissionalizante - Ministro Petrônio Portella, na cidade de Parnaíba - Piauí, que oferta essa modalidade de educação integrada ao ensino médio, com duração de quatro anos cada curso. Ao realizarmos tal investigação, em lócus, em análise de uma instituição de ensino profissionalizante a nível estadual, pretendemos refletir sobre o contexto em que está inserida a temática em pauta, dialogamos com as especificidades e as contradições que permeiam 0 processo de formação do jovem para o mercado de trabalho.

Neste cenário, ressaltamos a importância de perceber a escola como lugar/tempo de construção do conhecimento sistematizado, elaborado para um determinado fim, como um processo de institucionalização e formalização da educação, dentro das contradições/desigualdades de um espaço/tempo capitalista. Desta feita, algumas indagações norteiam nossas análises: a proposta de Educação Profissional observada atende, efetivamente, a demanda do mercado de trabalho parnaibano? Os cursos ofertados associam-se as especificidades do mercado de trabalho local? Ou seja, há possibilidade real de inserção/emprego? Quais os impactos da reestruturação produtiva nacional/transnacional para as políticas públicas de Educação Profissional? Quais as influências ideológicas/sociais/econômicas das relações 
capitalistas para a Educação Profissional parnaibana? Como as práticas de Educação Profissional intensificam as desigualdades sociais e dicotomizam as relações entre trabalho intelectual e trabalho manual? A qual segmento social pertencem os jovens pesquisados?

\section{EDUCAÇÃO, JUVENTUDE E TRABALHO EM PARNAÍBA/PI}

Diante da proposta de estudar/refletir a problemática que envolve a Educação Profissional, nos compete apresentar as categorias centrais elencadas para essa discussão - Educação, Juventude e Trabalho. Assim, privilegiamos a juventude como segmento social para a realização desse estudo, vez que, é a mais atingida pelas propostas de educação profissional e considerada potencial força de trabalho a ser formada. Para compreender a juventude enquanto segmento social é necessário apresentar o jovem como sujeito social e histórico, que constrói a sua sociabilidade na relação com o outro, que se reconhece protagonista das relações sociais e capaz de tomar decisões no âmbito educacional e socioeconômico, assim como explica Cavalcante (2011, p. 06), podemos compreender os jovens como sujeitos sociais, historicamente marcados pela construção de um "repertório de experiências" assim como o adulto, pela realidade social da qual fazem parte Nesse aspecto Lênin (1985) na sua obra intitulada "Sobre a Juventude" incube aos jovens a tarefa de construir uma nova sociedade, pois compreende esse segmento a partir das peculiaridades históricas e sociais as quais estão inseridos, propõe, entretanto, que se dê especial atenção à educação destinada a juventude, pois " só transformando radicalmente o ensino, a organização e a educação da juventude conseguiremos que os esforços da jovem geração tenham como resultado a criação de uma sociedade que não se pareça com a antiga"(p.38).

No entanto, no contexto da sociabilidade pautada nos valores da ordem capitalista a juventude muitas vezes é caracterizada apenas pela faixa etária ou como uma categoria passiva ${ }^{1}$ em processo de formação, é

\footnotetext{
${ }^{1}$ Cabe ressaltar que por passividade compreendemos o estado de ânimo social alheio as decisões políticas e não participativo das relações construídas historicamente.
} 
compreendida como uma fase de preparação para a vida adulta dependente das gerações anteriores no aspecto econômico, social e político. Essa visão tende a tornar a juventude vulnerável às decisões político-sociais que refletem na sua própria existência, desconsidera o papel da juventude enquanto sujeitos que constroem a sua sociabilidade. Nessa perspectiva, são elaboradas políticas de âmbito educacional que objetivam uma mera formação para o trabalho, negligenciando o caráter omnilateral ${ }^{2}$ do ser social ao receberem uma formação linear, em que são considerados apenas como potencial força de trabalho a ser formada para o mercado excludente e desigual, principalmente, os que são oriundos das classes mais baixas da sociedade. Isso contribui para que os jovens muitas vezes procurem se inserir no mercado de trabalho cada vez mais cedo, tanto por aspectos financeiros quanto por necessidade de autonomia e autoafirmação ${ }^{3}$.

As discussões sobre educação e trabalho tem se tornado pertinente na formação da juventude diante da conjuntura socioeconômica atual. Assim é que a educação proposta para a juventude parnaibana se configura como possibilidade de formação para o mercado de trabalho nas instituições de ensino profissionalizante, que oferecem cursos técnicos com o objetivo de suprir uma demanda de mão de obra do sistema capitalista de produção. Nesse contexto, as relações entre trabalho e educação se tornam inseparáveis na nova sociabilidade do capital, em que a educação apresenta caráter mercadológico, o trabalho se torna o responsável pela manutenção e desenvolvimento dos meios de produção e a juventude a principal força de produção a ser formada.

Embora a educação tenha se configurado como um instrumento de manutenção da estrutura social, econômica e política vigente, em que se reproduzem as relações de produção, é necessário compreender que a educação apresenta-se dialeticamente como uma possibilidade de superação

\footnotetext{
${ }^{2} \mathrm{O}$ conceito de omnilateralidade surge a partir de Marx, ao considerar que os indivíduos devem desenvolver-se como indivíduos completos e, portanto, a educação deve possibilitar a formação geral para a construção do ser social e, concomitantemente, oferecer uma formação para o trabalho. Segundo Manacorda(1996, p.78) a omnilateralidade compreende um desenvolvimento total, completo, multilateral, em todos os sentidos das faculdades e das forças produtivas, das necessidades e da capacidade da sua satisfação.

${ }^{3}$ Compreendemos autoafirmação como necessidade de reconhecer-se enquanto sujeito social e histórico.
} 
dessa perspectiva, vez que, a educação é um processo que perpassa todas as relações humanas, assim, para Saviani (2005, p.12) "dizer que a educação é um fenômeno próprio dos seres humanos significa afirmar que ela é ao mesmo tempo, uma exigência do e para o processo de trabalho, bem como é, ela própria um processo de trabalho". Contudo, devemos entender que trabalho, nesse sentido, tem uma perspectiva ontológica ${ }^{4}$, não no âmbito do capital que se apropria do trabalho como valor de troca e propiciador de mais-valia, o trabalho a qual se refere Saviani(2005) é o trabalho que distingue o ser humano dos outros animais, é uma ação transformadora sobre a natureza e realizadora do homem em seus anseios.

Essa concepção de trabalho nos remete aos escritos de Marx (2008, p. 62) de que "enquanto valor de uso, o trabalho é a condição natural da existência humana, a condição independente de todas as formas sociais, do intercâmbio da matéria entre o homem e a natureza", esse conceito de trabalho está relacionado, especificamente, as necessidades dos homens em extrair da natureza condições materiais para a produção da sua existência. No entanto, Marx (2008) compreende que o trabalho se torna trabalho social ao criar valor de troca, em que se constitui enquanto atividade intrínseca ao modo de produção, determinante das relações sociais. Nesta perspectiva, Macário (2003, p. 129) infere que "o homem enquanto indivíduo entra em relação com a natureza, reproduz sua existência pelo trabalho, sempre e necessariamente mediado por relações sociais determinadas". Então, no contexto da sociedade capitalista o trabalho é transformado em mercadoria e apropriado como trabalho assalariado.

Posto isso, nos propomos a verificar o perfil da juventude em aprendizado laboral que encontramos no CEEP em Parnaíba/PI, vez que, a proposta de Educação Profissional é destinada a esse segmento social, pois é nessa categoria que se lançam maiores esforços e recursos na formação para o trabalho. A juventude parnaibana que encontramos nessa instituiçãoencontra-se na faixa etária de 16 a 20 anos nos cursos diurnos. Essa

\footnotetext{
${ }^{4}$ A partir daperspectiva ontológica compreendemos o trabalho como categoria fundante do ser social. Nesse sentido o trabalho é uma especificidade do ser humano, pois é o trabalho que o diferencia de outros animais e, portanto, é através do trabalho que o homem se torna um ser social.
} 
faixa etária cresce nos cursos noturnos, principalmente, nos cursos do PROEJA ${ }^{5}$ com alunos numa faixa etária de 18 a 25 anos. A maioria desses jovens apresenta um perfil socioeconômico de baixa renda, geralmente moram numa casa com quatro ou cinco pessoas com uma renda mensal de pouco mais de três salários mínimos, o equivalente a $\mathrm{R} \$ 2.000$, por isso, veem na educação profissional a oportunidade de conseguir um emprego mais rápido e contribuir na renda da família.

Dessa forma, o filho da classe trabalhadora deve direcionar seus objetivos para o labor cotidiano que lhe é destinado por sua condição social determinada pelas relações de poder na sociedade, de acordo com Frigotto "a educação escolar é um aspecto da reprodução da divisão capitalista do trabalho. A organização escolar é uma réplica das relações de dominação e submissão da esfera econômica. (1993, p. 48), portanto a Educação Profissional é destinada aos jovens de baixa renda, com menos possibilidade de ascensão social.

\section{EDUCAÇÃO PROFISSIONAL E EMPREGABILIDADE EM PARNAÍBA/PI}

Neste âmbito, a Educação Profissional vem se constituindo como modalidade de ensino atraente aos jovens, vez que, o discurso da empregabilidade ${ }^{6}$ tem permeado a formação nesta modalidade impulsionado pelas metamoforses no mundo do trabalho contemporâneo. Nesta pespectiva, - CEEP em Parnaíba/Piauí oferta Educação Profissional na tentativa de atender as necessidades de formação exigidas no âmbito da relação educação para o trabalho, é portanto, uma instituição que tem se adequado as reformas empreendidas nas políticas públicas de Educação Profissional desde a década

\footnotetext{
${ }^{5}$ Programa de Integração da Educação Profissional ao Ensino Médio na Modalidade de Educação de Jovens e adultos. De acordo com Sousa (2011) o PROEJA, objeto do Decreto No 5.840 de julho de 2006, regulamenta a formação inicial e continuada de jovens e adultos trabalhadores em Educação Profissional técnica de nível médio, integrada ou concomitante. (p. 79)

${ }^{6}$ O termo empregabilidade gera controvérsias e tem sido usado com diversos sentidos. De acordo com Sales (2012, p. 88) "a noção de empregabilidade manifestou-se inicialmente em um contexto econômico marcado pela eliminação de postos de trabalho e pelo aumento da competição entre os trabalhadores, ao mesmo tempo em que exigiu competência técnica e científica para a força de trabalho se ajustar ao mercado de trabalho. Pode ser compreendido como a passagem de uma situação de desemprego para a de emprego, ou como capacidade de se manter em um mercado de trabalho em constante modificação".
} 
de 1990 para atender as demandas do mercado de trabalho ${ }^{7}$. Verificamos essas mudanças nos documentos da instituição onde consta que até o ano de 2006 era uma instituição que ofertava apenas o ensino técnico com duração de dois anos, desvinculado do ensino médio, essa proposta era amparada pelo Decreto 2.208/1997 que foi instituido durante a Reforma da Educação Profissional em 1997.

Entretanto, a partir de 2004 esse Decreto foi revogado e foi aprovado o Decreto 5.154/2004 que permite que a educação profissional técnica seja ofertada integrada ao ensino médio, todavia segundo Oliveira "esse Decreto permite variadas formas de organização da educação profissional técnica, desde a separação completa em relação ao ensino médio até a integração total"(2005, p.93). O CEEP, atualmente, oferta cursos na modalidade integrada com duração de quatro anos e o curso técnico com duração de dois anos, caso o egresso já tiver cursado o ensino médio regular, portanto, de acordo com o disposto no Paragráfo Único da LDB 9.394/96 da seção IV-A "A preparação geral para o trabalho e, facultativamente,a habilitação profissional poderão ser desenvolvidas nos próprios estabelecimentos de ensino médio ou em cooperação com instituições especializadas em educação profissional"(BRASIL, 1996).

Diante de tais reformas da Educação Profissional verificamos que a formação desses jovens tem acontecido de forma cada vez mais aligeirada, reforçando a dicotomia entre formação geral/integral e formação técnica, pois no novo currículo, as disciplinas básicas, como português, tiveram sua carga horária reduzida, vez que, era necessário a diminuição da carga horária dessas disciplinas para possibilitar a inclusão das disciplinas específicas em um curso com duração de quatro anos. Tomamos como exemplo o curso técnico de restaurante e bar em que consta que o objetivo geral é " promover capacitação profissional do aluno com a oferta do curso em nível técnico médio na área de eventos, permitindo o conhecimento científico e técnico, assim desenvolvendo

\footnotetext{
${ }^{7}$ Segundo Antunes (2006, p. 18) foi nos anos 1990 que a reestruturação produtiva do capital desenvolveuse intensamente em nosso país por meio da implantação de vários receituários oriundos da acumulação flexível e do ideário japonês com a intensificação dos sistemas just-in-timeekanban, do processo de qualidade total, das formas de subcontratação e de terceirização da força de trabalho que impulsionaram a entrada da robótica, telemática, informática e microeletrônica. Consequentemente, ocorreu uma reorganização da produção que passou a exigir um profissional mais qualificado.
} 
as competências necessárias para o bom desempenho profissional" ( PLANO DE CURSO, 2012, p. 5).

Neste sentido percebemos a negligência de uma formação ominilateral e a ênfase em uma inserção subalterna no mercado de trabalho, que privilegia a reprodução da técnica para o ato laborativo, e evidencia a permanente dicotomia entre o trabalho manual e o trabalho intelectual, para Gramsci (2010) "essa distinção é ideológica, na medida em que desvia a atenção das funções reais, no interior da vida social e produtiva, para os aspectos técnicos do trabalho" (p.21), vez que, a educação profissional é destinada aos filhos da classe trabalhadora, aos quais são relegadas as atividades técnicas/manuais de pouco prestígio nessa sociedade de classes, enquanto aos filhos da classe dirigentes reserva-se a escola do conhecimento mais elaborado, da apropriação da ciência e da educação humanista. Isto nos remete a tradição escolar brasileira pré-industrial que segundo Nosella (2002):

\begin{abstract}
A tradição escolar do Brasil pré-industrial era a escola humanista, socialmente distintiva, destinada as elites. Não havia necessidade de escolas para formar trabalhadores. Nesse sentido, não vale falar de dualidade de ensino do Brasil pré-industrial. Porém, com o advento da industrialização comumente datada dos anos 30 "final do século XX", organizou-se o ensino profissional com o objetivo de formar mão de obra para a indústria (técnicos). Dessa forma, estava instituída a dualidade escolar. (grifo meu, p.85).
\end{abstract}

A educação brasileira se construiu de forma elitista e excludente desde sua origem. O surgimento das escolas técnicas direcionadas para formar mão de obra decorrente do incipiente processo de industrialização tampouco extinguiu esse modelo, ao contrário, acentuou ainda mais a oposição entre o trabalho manual e o trabalho intelectual, a escola da técnica para o pobre e a escola da erudição para o rico. A Educação Profissional brasileira consolidouse com esse estigma, tendo passado por mudanças consideráveis para se adaptar as exigências do século XXI, ainda sustenta as heranças dessa dualidade. Nem mesmo a tentativa de construção de uma escola única ${ }^{8}$

\footnotetext{
${ }^{8}$ Em 1932, Antonio Gramsci propôs uma reforma escolar centrada na ideia de escola única, a que realiza num mesmo currículo a união entre o trabalho intelectual e o trabalho manual. Sua proposta refletia um grande debate daquele momento quando muitos teóricos da educação viam na ideia de escola única a
} 
proposta por AnísioTeixeira na década de 1950, idealizado a partir de Gramsci, não se efetivou pois se mostrou inviável no modelo de sociedade capitalista.

A Educação Profissional segundo Nosella (2002) passa por reformas na tentativa de harmonizar a escola humanista e a escola do trabalho, disso decorre a atual perspectiva do currículo dos cursos ofertados no CEEP que propõem uma organização por competências, série e itinerário formativo, em que a cada ano o aluno deverá ter desenvolvido competências que the permitirão a progressão para o ano seguinte até a sua formação ao final de quatro anos. No entanto, as práticas e os objetivos são contrastantes, na medida em que, as competências propostas dizem respeito ao perfil de profissional que se deve formar para suprir a demanda de mão de obra do mercado de trabalho, nesses termos é que o profissional técnico em serviços de restaurantee bar, por exemplo, "deverá estar hablitado a recepcionar, encaminhar e atender ao cliente no salão e bar do restaurante, bares e similares; coordenar a operação nos setores de bar e restaurante, controlar e inventariar estoques de bebidas e utensílios de salão e bar" (PLANO DE CURSO, 2012).

A partir de Guimarães ( 2006, p.188) compreendemos que "essa proposta curricular objetiva á educação das novas gerações e sua inserção na lógica da competitividade, da adaptção individual aos processos sociais e ao desenvolvimento de suas competências para a empregabilidade ou "laborabilidade". Tal pespectiva relaciona-se também as novas formas de organização do trabalho, em que é necessário um profissional polivalente e capaz de se adaptar as constantes mudanças do mundo do trabalho. Para Kuenzer (2003):

Competência deve ser a capacidade de agir, em situações previstas e não previstas, com rapidez e eficiência, articulando conhecimentos tácitos e científicos a experiências de vida e laborais vivenciadas ao longo das histórias de vida... vinculada à ideia de solucionar problemas, mobilizando conhecimentos de forma transdisciplinar a comportamentos e habilidades psicofísicas, e transferindo-os para novas situações; supõe, portanto, a capacidade de atuar mobilizando conhecimentos. (p. 02)

possibilidade de superar a tradicional divisão entre escola humanista para as elites e escola profissional para os trabalhadores. (NOSELLA, 2002, p.83) 
A ideia de competência está relacionada à relação entre teoria e prática, deve ser compreendida, portanto como a práxis no âmbito do trabalho, em que o currículo da Educação Profissional deve possibilitar uma formação a partir da práxis para desenvolver as competências necessárias para o mundo do trabalho. No entanto, o profissional técnico de nível médio é formado/treinado para executar as atividades que são, geralmente, pensadas por outros profissionais e os técnicos apenas as executam. Em que competências nesse sentido é desenvolver as atividades técnicas e laborais no âmbito das atribuições profissionais que Ihe compete pela sua formação, de orientação unilateral e linear.

A formação recebida pelos estudantes do CEEP distancia-se do ideal de competências proposta por Kuenzer (2003) e da tentativa de harmonizar a educação profissional com a humanista, vez que, percebemos que o modelo de Educação Profissional que está posto se constitui sob uma abordagem tecnicista e positivista, restringem a compreensão elementar das disciplinas de formação geral/integral, sob uma educação enciclopédica e reprodutivista, que não possibilita o desenvolvimento de conhecimentos cientificos efetivos e elaborados, além de negligenciar a compreensão política das relações de poder que permeiam a realidade histórica e social. Prioriza-se a apreensão da técnica enquanto instrumento de inserção no mercado de trabalho, nos fazendo relembrar o que Frigotto (1993) revela sobre a teoria do capital humano:

No âmbito propriamente educacional e pedagógico, a teoria do capital humano vai ligar-se à toda a perpectiva tecnicista que se encontra em pleno desenvolvimento na década de 50 . Nesse aspecto há um duplo reforço. A visão do capital humano vai reforçar toda a perspectiva da necessidade de redimir o sistema educacional de sua "ineficiência" e, por sua vez, a perspectiva tecnicista oferece a metodologia ou a tecnologia adequada para constituir o processo educacional como um investimento - a educação geradora de um novo tipo de capital - 0 "capital humano". A educação para essa visão se reduz a um fator de produção. (FRIGOTTO, 1993, p. 121).

A Educação Profissional tem se constituído a partir da concepção da teoria do capital humano na sua dimensão formadora de jovens trabalhadores 
que devem estar aptos para a inserção no modelo capitalista de produção. Dessa forma, as competências têm sido organizadas concomitantes as necessidades do mercado de trabalho, assim é que o CEEP oferta cursos que estão relacionados aos setores que exigem maior demanda de mão de obra e que oferecem maiores possibilidades de emprego no mercado local, como por exemplo, nas áreas de Informática; manutenção e suporte; edificações; nutrição e dietética; análises clínicas; enfermagem; saúde bucal; serviço de restaurante e bar e hospedagem. Essa instituição de ensino mantem convênios com empresas para a realização dos estágios, e segundo a Gestora (2012) "há estagiários que conseguem emprego na própria empresa em que realizaram o estágio", o que evidencia o caráter mercadológico que permeia o processo de formação desses jovens.

Através deb questionário aplicado com 10 estudantes do curso de informática, percebemos que eles veem nesse curso a possibilidade de inserção no mercado de trabalho, têm clareza sobre o objetivo da educação que recebem. A turma pesquisada estava no primeiro ano do curso e, portanto, a expectativa em relação ao curso para conseguir um emprego é grande, um dos estudantes ao responder sobre a perspectiva de emprego na sua área de formação e porque escolheu fazer esse curso relata que:

O curso técnico em informática é bom, acho interessante a área de informática, e em Parnaíba há necessidade de profissionais nessa área e será mais fácil ter um emprego quando concluir o curso de quatro anos, pois as empresas sempre precisam de um técnico. $\mathrm{E}$ conheço pessoas que estudaram aqui e hoje estão trabalhando na sua área de formação. (estudante A de informática, agosto 2012).

É possível compreender que os estudantes que ingressam nessa instituição são capturados pela falácia da educação como possibilidade de inserção no mundo de trabalho, sua compreensão de formação no âmbito da instituição escolar é permeada pela relação com o processo de produção capitalista que se apropria ideologicamente da educação como espaço de reprodução das relações sociais e produtivas vigentes na sociabilidade do capital, vez que, assim como propunha Gramsci (2010) compreendemos que a escola não se explica por ela mesma, mas pela sua relação com a sociedade, 
com a economia e com a política. Em confluência com a perspectiva da teoria do capital humano verificamos o aspecto unilateral da formação desses jovens, que restringem a compreensão de educação à possibilidade/oportunidade de inserção no mudo do trabalho, a escola é responsabilizada pela formação de sujeitos aptos a disputarem uma vaga no competitivo mercado de trabalho, desse modo:

\begin{abstract}
A institucionalização do preparo profissional no âmbito escolar decorre das necessidades do sistema social capitalista de veicular o conhecimento utilizado na produção industrial e regulamentar a força de trabalho, legitimando a estrutura social dessemelhante. A escola cumpre a função instrumental de transmitir os conhecimentos minimamente necessários a produção, e, ao mesmo tempo desempenha um mister ideológico reprodutivo, permitindo justificar as desigualdades sociais em favor da escolarização com vistas a distribuir as diferentes ocupações com seus patamares salarias e prestígio social distintos. (OLIVEIRA, 2005, p. 75).
\end{abstract}

Nessa perspectiva, a juventude da classe trabalhadora ver na Educação Profissional a oportunidade de mobilidade social, pois proporciona uma formação para o mundo do trabalho, e atende a demandas de mão de obra, com uma educação utilitarista. Os relatos desses jovens, cuja identidade preservamos com as letras do alfabeto e relacionam-se ao desejo de um emprego e de melhorar a condição socioeconômica a que estão submetidos, assim é que o estudante "A" do curso de informática (agosto, 2012) decidiu fazer esse curso porque "quero algo melhor na minha vida e ajudar nas despesas da família, mas sei que para conseguir isso preciso me esforçar muito para ser um ótimo profissional". Segundo Arrais Neto (2004) essa concepção surge do fato de tornar responsabilidade individual o que deveria ser garantido por políticas públicas e transfere-se ao individuo a exclusão direta do mundo produtivo, pois o sujeito deve desenvolver competências profissionais e se mostrar interessante ao mercado de trabalho para atender as exigências da "empregabilidade".

Todavia, nem sempre a instituição oferece uma estrutura adequada para o aprendizado e formação, pois há cursos que muitas vezes não oferecem condições adequadas à realização de aulas práticas, que comprometem a qualidade da formação desses jovens, nesse ponto durante a aplicação do 
questionário um estudante ao ser indagado sobre o nível de qualidade do seu curso relata que considera:

O curso com um nível regular, pois os professores são bons e capacitados, mas a escola não está com uma estrutura boa, e fica difícil realizar as aulas práticas de informática sem um bom laboratório, e o que acontece é que não tem computador para todos os alunos e temos que dividir um computador com duas ou três pessoas. (estudante "B" do curso de informática, agosto 2012)

Percebemos que embora tenha havido maiores investimentos, e incentivos do governo para ampliar a modalidade de Educação Profissional nos últimos 10 anos, ainda encontramos muitas deficiências e problemas no que concerne a estrutura dessa instituição pública que oferta Educação Profissional, vez que, recebe recursos diretamente da esfera estadual. Além disso, em uma entrevista realizada com estudantes que já concluíram o curso percebemos nos relatos dos mesmos que têm se confrontado com as dificuldades de se inserir no mercado de trabalho em Parnaíba/PI. Para o aluno "C" que concluiu o curso em 2010 nos seus relata que:

\footnotetext{
Não me considero qualificado, pois as disciplinas e professores não correspondiam com o que era exigido no mercado de trabalho, ou seja, métodos e assuntos ultrapassados, logo que na informática há uma evolução constante de conceitos, métodos e máquinas. No momento não me encontro empregado na área, mas já trabalhei na área e era remunerado pela produção (quantidade de computadores que apareciam para manutenção). Além disso, é diferenciado conseguir um emprego com essa formação, pois a formação é aligeirada e de curto prazo para poder dar conta das demandas do mercado de trabalho.(setembro, 2012).
}

A partir desse relato afirmamos que a exigência do mercado de trabalho exclui até mesmo profissionais que têm um diploma de curso técnico, que, no entanto, não se consideram suficientemente preparados e qualificados com competências para se adequar as constantes mudanças nas relações de produção. Por outro lado, esse fenômeno relaciona-se ao fato de que a educação sozinha não consegue resolver os problemas de emprego/desemprego, pois a problemática da empregabilidade está relacionada às politicas públicas de oferta e criação de postos de trabalho. Para Pochmann (2006) o mercado de trabalho tornou-se mais competitivo, 
sobretudo diante de uma oferta de mão-de-obra com mais escolaridade. Mas a permanência no emprego dos mais qualificados não implicou, necessariamente, a adequação perfeita entre formação e ocupação (p. 71). A partir disso, refletimos que o desemprego atinge, principalmente, os jovens com baixo nível de escolaridade e os mais pobres.

\section{CONSIDERAÇÕES FINAIS}

Ao considerar a Educação Profissional como possibilidade de formação para o mercado de trabalho os jovens da classe trabalhadora recebem uma formação que negligencia o aspecto omnilateral da educação, que deve proporcionar um desenvolvimento integral em todas as totalidades e potencialidades humanas. A instrução escolar segundo Saviani (2005, p. 15) "deve propiciar a aquisição dos instrumentos que possibilitam o acesso ao saber elaborado (ciência) bem como o próprio acesso aos rudimentos desse saber". No entanto, ao refletir acerca do processo de formação que permeia a educação dos jovens da classe trabalhadora analisamos que esses pressupostos educacionais encontram-se distantes no processo de formação destes, vez que, a educação destinada a esses jovens acontece de forma aligeirada, pois a necessidade de conseguir um emprego é eminente, vez que a suas condições socioeconômicas os levam a procurar um emprego para ajudar na renda familiar e até mesmo para manter meios de sobreviver.

Além disso, muitos são os jovens que ao concluir um curso profissionalizante continuam desempregados, em decorrência da competitividade e escassez de postos de trabalho, ocasionados pelas transformações ocorridas no mundo do trabalho a partir da década de 1990 no Brasil, com a onda de desemprego estrutural, com a reestruturação produtiva e as novas formas de reorganização do trabalho, com a entrada da robótica, informática, telemática e mecatrônica nas indústrias e nos mais diversos setores empregáveis, como por exemplo, a indústria têxtil, automobilística e os bancos, intensificou-se a substituição do trabalho humano pela máquina, ocasionou o enxugamento de mão de obra das empresas a fim de aumentar a produtividade e diminuir os gastos com funcionários, ao mesmo tempo em que 
causou o desemprego em massa nesses setores e passou a exigir um profissional polivalente e mais qualificado. $O$ mundo do trabalho se tornou ainda mais excludente e competitivo. Para Oliveira (2003) "o quadro de desemprego aparece como forte agente disciplinador da força de trabalho, levando o trabalhador a sujeitar-se às formas mais precárias de emprego, aceitar intenso ritmo de trabalho e comprometer-se com os fins da empresa" (p.82/83).

Nesse contexto, a Educação Profissional passa a ser pensada como possibilidade para impulsionar a produtividade,em que 0 mercado de trabalho,ao mesmo tempo, que exige maior escolaridade e formação de uma mão de obra mais qualificadapara o eminente crescimento industrial do país, contraditoriamente, ocasiona ondas de desemprego. De acordo com Pochmann (2005, p. 73)"as atuais politicas de emprego precisam ser urgentemente reformuladas para se adequarem melhor a esse quadro nacional".

\section{REFERÊNCIAS}

ANTUNES, Ricardo (org.). Riqueza e miséria do trabalho no Brasil - São Paulo: Boimtempo, 2006.

ARRAIS, Enéas Neto. Mundo do Trabalho: debates contemporâneos. Fortaleza: Editora UFC, 2004.

BRASIL. Lei de Diretrizes e Bases da Educação Nacional. MEC, 2008. Disponível em:<http://portal.mec.gov.br/>. Acesso em: 22 mar. 2012.

CEEP, Centro Estadual de Educação Profissional Ministro Petrônio Portela. Proposta político-pedagógica.Parnaíba/Piauí, 2008.

CAVALCANTE, Luciana Matias. Formação dos jovens no ensino médio: perspectiva da juventude e configuração do ambiente de formação que finaliza a educação básica. Disponível em: 
<http://www.pe.senac.br/ascom/congresso/salao/Congresso2011. > Acesso em: 20 out. 2012.

FRIGOTTO, Gaudêncio. A produtividade da escola improdutiva. $4^{a}$ ed. São Paulo: Cortez, 1993.

GRAMSCI, Antônio. Escritos Políticos. Vol. I. Organização e Tradução Carlos Nelson Coutinho. - Rio de Janeiro: Civilização Brasileira, 2004.

KARL, Marx. Contribuição à crítica da economia política. Tradução e introdução de Florestan Fernandes. 2 ed. São Paulo: Expressão Popular, 2008.

KUENZER, Acacia. Competência como Práxis: os Dilemas da Relação entre Teoria e Prática na Educação dos Trabalhadores. Disponível em: <http://www.senac.br/BTS/291/boltec291b.htm>. Acesso em: 04 out. 2012.

LÉNINE, V.I .Sobre a Juventude. Edições da Agência de impressa Nóvosti Moscovo, 1985.

MACÁRIO, Epitácio. Trabalho e mediação social. In: MENEZES, Ana Maria Dorta de. FIGUEIREDO, Fabio Fonseca (Orgs.). Trabalho, sociabilidade e educação: uma crítica à ordem do capital. Fortaleza: Editora UFC, 2003. p. 120-148.

MONASTA, Atillo. Antonio Gramsci. Tradução: Paolo Nosella. Recife, Editora Massangana. 2010.

NOSELLA, Paolo. Qual compromisso político? Ensaios sobre a educação pós-ditadura. 2 ed. Revista e ampliada. Bragança Paulista: EDUSF, 2002.

OLIVEIRA, Elenilce Gomes de. Reestruturação produtiva e formação profissional. In: MENEZES, Ana Maria Dorta de. FIGUEIREDO, Fabio Fonseca 
(Orgs.). Trabalho, sociabilidade e educação: uma crítica à ordem do capital. Fortaleza: Editora UFC, 2003. p. 79-89.

OLIVEIRA, Elenilce Gomes de (Orgs.). Educação profissional: análise contextualizada. Fortaleza: CEFET-CE, 2005.

POCHMANN, Márcio. Desempregados do Brasil. In: ANTUNES, Ricardo (org.). Riqueza e miséria do trabalho no Brasil. São Paulo: Boimtempo, 2006.

SALES, Francisco. Planfor: Política compensatória para a inclusão na informalidade. Fortaleza, Edições UFC, 2012.

SAVIANI, Dermeval. Pedagogia histórico-crítica. 9 ed. Campinas: Autores Associados, 2005. (Coleção Educação Contemporânea).

SOUSA, Antonia de Abreu; LIMA, Claudio Ricardo Gomes de; OLIVEIRA, Elenilce Gomes de. Política pública para a educação profissional e tecnológica no Brasil. Fortaleza: Edições UFC, 2011.

i. Tânia Serra Azul Machado Bezerra. Professora Adjunta da Universidade Federal do PiauíUFPI/Parnaíba. Doutora em Educação Brasileira. taniasamb@yahoo.com.br;

ii. Cloris Violeta Alves Lopes. Professora Assistente da Universidade Federal do Piauí/Parnaíba. Mestre em Educação Brasileira; cloris-carlos@uol.com.br.

iii. Maria Luzirene Oliveira do Nascimento. Concludente do Curso de Pedagogia da Universidade Federal do Piauí-UFPI/Parnaíba. e-mail: biolyzzi@hotmail.com

RECIBIDO: 21.12 .12

APROVADO 07.01 .13 